\title{
DESAFIOS E POSSIBILIDADES NA UTILIZAÇÃO DO MÓDULO ESPECIAL DO SISTEMA INTEGRADO DE GESTÃO EDUCACIONAL DO AMAZONAS
}

\author{
CHALLENGES AND POSSIBILITIES IN THE USE OF THE SPECIAL MODULE OF \\ THE INTEGRATED EDUCATIONAL MANAGEMENT SYSTEM OF AMAZONAS
}

\section{RETOS Y POSIBILIDADES EN EL USO DEL MÓDULO ESPECIAL DEL SISTEMA INTEGRADO DE GESTIÓN EDUCATIVA DE AMAZONAS}

\author{
Ana Patricia Peinado e Silva ${ }^{1}$ \\ Secretaria de Estado de Educação do Amazonas, SEDUC/AM
}

\section{Resumo}

Este artigo tem como objetivo apresentar as possibilidades administrativas e pedagógicas na utilização de um sistema informatizado na gestão escolar com foco na inclusão do aluno com necessidade especial. Nesse sentido, a Secretaria de Estado de Educação e Desporto (SEDUC/AM) desenvolveu e implantou o Sistema Integrado de Gestão Educacional do Amazonas (Sigeam), que traz, dentre outros serviços, um módulo chamado Especial. Esse módulo é composto de serviços e relatórios gerenciais que têm por finalidade subsidiar a gestão escolar e a macrogestão da SEDUC/AM, nas tomadas de decisão sobre o público-alvo da educação especial. É importante destacar que o interesse neste tema surgiu a partir de formações ministradas por esta pesquisadora aos gestores escolares, nas quais foram constatadas que estes, não só, não tinham acesso a todos os serviços deste módulo, como sequer conheciam, na íntegra, aqueles os quais tinham acesso. Assim sendo, considerando esses fatores como condicionantes para o pleno uso do sistema, pondera-se que não basta ter um sistema informatizado, como também é fundamental que se conheçam as possibilidades administrativas e pedagógicas a ele pertinentes, além de possibilitar acesso pleno aos gestores. No que concerne à pesquisa, utilizou-se metodologia de natureza qualitativa exploratória e descritiva, sendo embasada por estudos

\footnotetext{
${ }^{1}$ Possui graduação em Letras - Língua e Literatura Portuguesa pela Universidade Federal do Amazonas (1999). Atualmente é professora formadora e revisora textual na Coordenação de Formação a Distância (CEAD), no Centro de Formação Profissional Padre José de Anchieta (CEPAN), da Secretaria de Estado de Educação do Amazonas (SEDUC/AM). Tem experiência na área de Educação, com ênfase em tecnologias aplicadas à educação, bem como, em docência do ensino fundamental e médio em Língua Portuguesa e Língua Inglesa, também desenvolveu atividades, ministrando aulas em plataformas $E A D$, atuou com tutora em especialização "mídias aplicadas à educação" pela Universidade Federal do Amazonas. No que se refere à atividades administrativas, atuou como assessora na diretoria do Departamento de Gestão Escolar, no Centro de Formação Padre Josè de Anchieta e como Assessora Administrativa no Gabinete Pedagógico da SEDUC/AM em 2018. Sua dissertação versou sobre a gestão de alunos com necessidades especiais por meio do Sistema Integrado de Gestão Educacional do Amazonas (SIGEAM). Também, atuou como orientadora de Trabalhos de Conclusão de Curso em Letramento Digital pela Universidade Estadual do Amazonas. http://lattes.cnpq.br/8786370725454907
} 
bibliográficos da temática educação especial, no uso das NTICs e das possibilidades advindas da utilização de sistemas. Destarte, os achados dessa pesquisa trouxeram informações que podem possibilitar à SEDUC/AM ser mais assertiva nas políticas implementadas na área da educação inclusiva.

Palavras-chave: educação especial; Sigeam; gestão escolar.

\begin{abstract}
This article aims to present the administrative and pedagogical possibilities in the use of a computerized system in school management focused on the inclusion of students with special needs. In this sense, the State Board for Education and Sport (SEDUC/AM) developed and implemented the Amazon Integrated Educational Management System (Sigeam), which brings, among other services, a module called Special. This module is composed of services and management reports that aim to subsidize school management and the macromanagement of SEDUC/AM, in decision-making about the target audience of Special Education. It is important to highlight that the interest in this theme arose from training given by this researcher to school managers, in which it was found that they, not only, did not have access to all the services of this module, but did not even know, in full, those to whom they had access. Therefore, considering these factors as conditioning for the full use of the system, it is considered that it is not enough to have a computerized system, but it is also essential to know the administrative and pedagogical possibilities pertinent to it, besides allowing full access to managers. As for the research, we used a methodology of exploratory and descriptive, qualitative nature, based on bibliographic studies of the theme of special education, the use of NTICs and the possibilities resulting from the use of systems. Thus, the findings of this research brought information that can enable SEDUC/AM to be more assertive in the policies implemented in the area of inclusive education.
\end{abstract}

Keywords: Special education; Sigeam; school management.

\title{
Resumen
}

Este artículo tiene como objetivo presentar las posibilidades administrativas y pedagógicas en el uso de un sistema informático en la gestión escolar con un enfoque en la inclusión de estudiantes con necesidades especiales. En este sentido, la Secretaría de Estado de Educación y Deporte (SEDUC / AM) desarrolló e implementó el Sistema Integrado de Gestión Educativa de Amazonas (Sigeam), que trae, entre otros servicios, un módulo denominado Especial. Este módulo está compuesto por servicios e informes de gestión que tienen como objetivo subsidiar la gestión escolar y la macrogestión de la SEDUC / AM, en la toma de decisiones sobre el público objetivo de la educación especial. Es importante resaltar que el interés en esta temática surgió a partir de la capacitación brindada por esta investigadora a los administradores escolares, en la cual se encontró que no solo no tenían acceso a todos los servicios de este módulo, ya que ni siquiera conocían, en su totalidad, los a los que tenían acceso. Por tanto, considerando estos factores como condiciones para el pleno uso del sistema, se considera que no basta con contar con un sistema informatizado, sino que también es fundamental conocer las posibilidades administrativas y pedagógicas relevantes, además de permitir el pleno acceso a los directivos. En cuanto a la investigación, se utilizó una metodología cualitativa exploratoria y descriptiva, basada en estudios bibliográficos sobre el tema de la educación especial, en el uso de las NTICs y las posibilidades que se derivan del uso de sistemas. Así, los hallazgos de esta investigación aportaron información que puede permitir a la SEDUC / AM ser más asertiva en las políticas implementadas en el ámbito de la educación inclusiva. 
Palabras claves: educación especial; Sigeam; gestión escolar. INTRODUÇÃO

Nos últimos anos, houve grande desenvolvimento das Novas Tecnologias Digitais da Comunicação e da Informação (NTDICs). A disseminação da internet reduziu distâncias no mundo e proporcionou a massificação do acesso às tecnologias, contexto no qual o Brasil está inserido. Assim, o desenvolvimento das NTDICs possibilitou avanços significativos em vários setores da economia nacional, nas últimas décadas. $\mathrm{Na}$ educação, esse processo se refletiu de forma acentuada e positiva, contribuindo decisivamente para o avanço nos processos de ensino e aprendizagem, na formação dos profissionais da educação, na gestão escolar, na gestão administrativa e pedagógica das secretarias de educação e no processo de inclusão social.

Nesse contexto, o presente artigo tem por objetivo apresentar o Sistema de Gestão Educacional Integrado do Amazonas (Sigeam) enquanto ferramenta tecnológica para a gestão administrativa e pedagógica dos processos de inclusão da pessoa com necessidades especiais nas escolas públicas do estado do Amazonas.

No que se refere à metodologia, a pesquisa foi desenvolvida por meio de abordagem qualitativa, do tipo estudo de caso, foi escolhida essa forma ${ }_{\bar{s}}$ por permitir análise de dados não contáveis. Segundo Minayo (2001, p. 22), “a abordagem qualitativa aprofunda-se no mundo dos significados das ações e das relações humanas, por um lado não perceptível e não captável em equações, médias e estatísticas".

Posto isso, este artigo está estruturado da seguinte forma: o cenário da educação especial no Brasil e no Amazonas, com ênfase nas legislações, para a compreensão dos processos que envolvem o contexto administrativo e pedagógico em sua gestão na educação; o Sigeam, suas funcionalidades, usos nos departamentos e nas escolas; a utilização do módulo Especial e, finalmente, o uso das Novas Tecnologias Digitais da Informação e Comunicação (NTIDCs) pela SEDUC/AM.

A presente pesquisa pretende, sobretudo, fazer um estudo sobre dois aspectos da educação que se encontram e se completam na rede estadual de ensino do Amazonas: a utilização das NTDICs por meio do Sigeam e a educação especial.

\section{O cenário da educação especial no Brasil}

O cenário da inclusão e das políticas públicas desenvolvidas para a pessoa com necessidade especial, no Brasil, apresenta a inclusão no atendimento às legislações Revista Amazônida, Manaus, AM, vol. 6, n 1. p.01 - 21, 2021 
vigentes no país. Nesse sentido, observa-se que não houve mudança desses documentos nos últimos anos e, segundo Pedro Goergen, in Januzzi (2012, s/p), "a história da educação brasileira mostra-nos que a educação especial foi centro de atenção e preocupação apenas nos momentos e na medida exata em que dela sentiram necessidade os segmentos dominantes da sociedade".

Apesar disso, é evidente que as legislações são imprescindíveis na garantia dos direitos da pessoa com necessidades especiais e sua efetivação envolve a ação de vários atores, dentre eles, os gestores escolares que, por estarem na linha de frente, figuram entre os principais responsáveis pelo efetivo cumprimento dos ditames legais.

Para situarmos a educação especial no contexto das leis, serão mencionadas algumas legislações que foram criadas para o atendimento ao aluno com necessidades especiais, no contexto da inclusão educacional. Por este ângulo, o Plano Nacional de Educação (PNE), de 2014, das 20 metas, tem a meta 4 direcionada para a educação especial e pretende no decorrer dos dez anos de vigência do plano:

[...] universalizar, para a população de 4 (quatro) a 17 (dezessete) anos com deficiência, transtornos globais do desenvolvimento e altas habilidades ou superdotação, o acesso à educação básica e ao atendimento educacional especializado, preferencialmente na rede regular de ensino, com a garantia de sistema educacional inclusivo, de salas de recursos multifuncionais, classes, escolas ou serviços especializados, públicos ou conveniados. (PNE, 2014)

A meta está alinhada com a Lei de Diretrizes e Bases da Educação (LDB 9.394/96), que regulamenta, nos Artigos 58, 59 e 60, o atendimento dos alunos com necessidades especiais nas escolas públicas.

Além disso, a Lei Federal o 13.146/2015 que institui o Estatuto da Pessoa com Deficiência e imprime a garantia de direitos aos brasileiros com "algum" grau de deficiência (BRASIL, 2015). Essa lei passou a vigorar em janeiro de 2016, buscando conferir "autonomia social" e possibilitando a esses indivíduos uma "vivência cidadã" em nível de equidade com os demais, independentemente de suas limitações físicas e mentais. Salienta-se que existe a garantia do direito, embora nem sempre a pessoa com necessidade especial lance mão desse direito.

Os Artigos 27 e 28, da Lei Federal ํㅜ13.146/2015, que versam sobre os direitos à educação, reforçam a educação inclusiva, enfatizando que o atendimento ao aluno especial é um direito (BRASIL, 2015). Entretanto, para isso, faz-se necessário buscar meios de facilitar os processos administrativos e pedagógicos que entremeiam a inclusão, 
desde o processo de matrícula. No que concerne às ações dos estados e ressaltando como funcionam as políticas inclusivas no Amazonas, o subtópico a seguir irá abordar a Resolução no 138/2012 do Amazonas e relacioná-la ao uso do Sigeam.

\subsection{A política da educação inclusiva no Amazonas: Resolução no 138/2012 e o}

\section{Sigeam}

A Resolução no 138/2012, que regulamenta a educação especial no Amazonas, está alinhada com as legislações vigentes no país, está em conformidade com a LDB 9.394/96; no Parecer do Conselho Nacional de Educação (CNE) da Câmara de Educação Básica (CEB) no 17/2001; na Resolução no 04 de 07/2010, do mesmo CNE, do Decreto no 7.611 de 11/2011; e, também, no Artigo 14 e seus parágrafos da Resolução 99/97 do Conselho Estadual de Educação do Amazonas (CEE/AM) (AMAZONAS, 2012).

Nesse contexto, as escolas estaduais do Amazonas fazem atendimento inclusivo ao aluno com necessidades especiais, considerando a Resolução no 138/2012, que normatiza e busca a garantia de educação equitativa aos educandos com deficiências, transtornos globais e altas habilidades/superdotação. A legislação define as diretrizes que regulam a educação especial do sistema de ensino do Amazonas, assegurando os serviços de educação para as pessoas com deficiência, com início na faixa etária de 0 a 5 anos, na educação infantil, creche e pré-escola (AMAZONAS, 2012).

Conforme a regulamentação, o poder público desenvolvera como política de atendimento escolar a ampliação da inclusão de alunos com necessidades especiais na rede pública regular de ensino, independentemente do apoio às instituições sem fins lucrativos, que passam a ter atuação exclusiva na oferta de Atendimentos Complementares. O art. 2ํㅡ da Resolução nำ 138/2012 estabelece, em consonância com a Política Nacional de educação especial na perspectiva da educação inclusiva (MEC, 2008), que:

Art. $2^{\circ}$ - A educação especial perpassa todos os níveis, etapas e modalidades da educação básica e superior, realiza o Atendimento Educacional Especializado, disponibiliza os serviços e recursos próprios desse atendimento e orienta alunos e profissionais quanto à utilização desses recursos nas turmas comuns do ensino regular. (AMAZONAS, 2012)

A Resolução enumera as deficiências físicas e mentais que perpassam pela educação especial, que são: (i) Deficiência sensorial física, intelectual e múltipla; (ii) Transtornos Globais do Desenvolvimento (síndromes); (iii) Altas Habilidades/Superdotação além de trazer o conceito de pessoa com deficiência em Revista Amazônida, Manaus, AM, vol. 6, n 1. p.01 - 21, 2021 
consonância com a Declaração de Salamanca (UNESCO, 1994).

O art. 5ํㅡ, alinhado com a Resolução CNE/CEB № 2, de 11 de setembro de 2001, sugere que as instituições educacionais, para realizar a identificação adequada dos alunos com necessidades especiais, devem avaliá-los, por meio de assessoramento técnico, valendo-se da experiência do seu corpo técnico e técnico-pedagógico, serviços especializados responsáveis pela educação especial do respectivo sistema e com participação da família e dos serviços de Saúde, Assistência Social, Trabalho, Justiça e Esporte, do Conselho Tutelar e do Ministério Público, caso seja necessário (BRASIL, 2001).

O art. 60 recomenda que as Secretarias de Educação e demais instituições educacionais estabeleçam parcerias com instituições de ensino superior para pesquisas e estudos de caso, com o objetivo de aprofundar o conhecimento do processo educativo dos alunos com necessidades especiais (AMAZONAS, 2012).

Percebe-se que, apesar de explicitar os direitos do aluno especial e nominar as deficiências físicas por ela amparada, a referida Resolução é omissa quando a especificidade perpassa pelo aluno com superdotação, pois não regulamenta o avanço de estudos para este aluno nas escolas, mas inclui a superdotação e as altas habilidades como "necessidades especiais", em conformidade com a Resolução CNE/CEB n 2/200 (BRASIL, 2000).

A Resolução também determina que turmas inclusivas de crianças com graves transtornos no desenvolvimento devem ter a figura do auxiliar da vida escolar e serviço de apoio pedagógico especializado, complementar ou suplementar nas salas de recursos multifuncionais ou centros de apoio especializados (AMAZONAS, 2012).

Consoante a sistemas de informação, a Resolução informa:

Art. 10 - Deverão ser criados sistemas de informação e ser estabelecida interface com os órgãos governamentais responsáveis pelo Censo Escolar e pelo Censo Demográfico, para atender a todas as variáveis implícitas à qualidade do processo formativo dos alunos, público alvo da educação especial.

Art. 11 - Os sistemas de ensino devem matricular todos os alunos, cabendo às escolas assegurar as condições necessárias, conforme o art. ${ }^{\circ}$ desta Resolução, assegurando uma educação de qualidade para todos, reconhecendo e valorizando as singularidades, diferenças e potencialidades no processo de ensino e aprendizagem. (AMAZONAS, 2012).

Nessa conjuntura, identifica-se o Sigeam como o sistema a ser utilizado para promover o suporte cabível, evidenciado na Resolução. Visto que o sistema possibilita ao gestor escolar acesso a dados e informações relevantes para a compreensão do 
"movimento" que concerne à mudança do vínculo escolar do aluno depois da data de referência do Censo Escolar que pode ser: transferência (oriundo de outro escola), deixou de frequentar e falecido, da educação especial na escola, propiciando maior controle no atendimento a esses alunos.

No que se refere ao suporte pedagógico ao aluno com necessidade especial, o sistema permite dimensionar a premência profissional, entre outras coisas, visto que, em alguns casos, obedecendo à legislação, torna-se necessário solicitar da SEDUC/AM, 0 técnico de apoio e o orientador da vida escolar para esse aluno, que é a responsável pela gestão dos profissionais da educação no Amazonas.

O estabelecimento do Sigeam também promove integração com o sistema do Censo educacional, atendendo ao que está descrito no Artigo $10^{\circ}$ da referida Resolução, dado que é o Sigeam que migra os dados educacionais para o Educacenso, o que facilita os processos existentes e evita retrabalho (AMAZONAS, 2012).

Para Silva:

Na educação, com o SIGEAM, a SEDUC/AM dá um exemplo da utilização de recursos de tecnologia da informação e da comunicação em favor da implementação de políticas públicas. Implantou um sistema adequado às suas necessidades e que está em constante processo de aprimoramento a partir da contribuição dos seus utilizadores e das informações gerenciais que nele são geradas, permitindo a essa mesma SEDUC/AM, ser mais assertiva na sua área de atuação. (SILVA, 2016, p. 26)

Dessa forma, temos um sistema disponível para gerenciar as informações, em conformidade ao que orienta a Resolução no 138/2012.

Entretanto, sabe-se que não basta ter um sistema com inúmeras informações disponibilizadas, é necessário que estas estejam alinhadas com o fazer administrativo e pedagógico. Por isso, investigou-se quanto à contemplação do sistema às exigências da legislação e os seus possíveis usos, pois no contexto escolar, é condição sine qua non que o gestor se aproprie de informações que forneçam respaldo para suas ações considerando a efetividade delas, ou seja, precisam conhecer a legislação, bem como os serviços disponíveis no sistema para o seu atendimento. Para explicitar melhor o sistema, o próximo tópico contará com um breve histórico do Sigeam e suas possibilidades de uso.

\section{Sigeam}

O Sigeam foi desenvolvido em 1998 como um sistema informatizado de controle acadêmico para auxiliar gestores, secretários e pedagogos a visualizarem as dimensões que envolvem a escola como um todo, bem como para promover o aprimoramento das atividades de gestão, técnicas e administrativas. Para Silva (2016, p.38), o sistema tem 
grande abrangência no que se refere aos processos ocorridos na administração, tanto da escola, quanto da própria administração do macrossistema.

É importante saber que o Sigeam está divido em módulos de serviços, que são nominados de acordo com sua função, de forma mnemônica. Dentre os serviços utilizados pela escola, encontra-se o módulo "GESTÃO", no qual estão inseridos serviços para auxiliar o gestor escolar, e entre eles está o "Especial", que é um módulo de serviços que tem por objetivo facilitar o atendimento do aluno com necessidades especiais.

Embora o sistema esteja repleto de serviços que podem oferecer celeridade às atividades administrativas e mesmo pedagógicas, observa-se que não oferece uma interface amigável, possui tela escura, com poucos recursos visuais, dependendo basicamente do que o aplicativo/emulador oferece quanto às configurações visuais (ver Figura 1). Foi desenvolvido desta forma porque se levou em consideração a baixa qualidade de internet no estado do Amazonas, pois assim poderia garantir-se que mesmo as escolas com acesso limitado a esse serviço pudessem utilizá-lo. O acesso ao sistema se dá por meio de softwares que emulam terminal, por exemplo, o EXTRA e o PW3270.

\section{Figura 1 - Tela inicial do Sigeam}

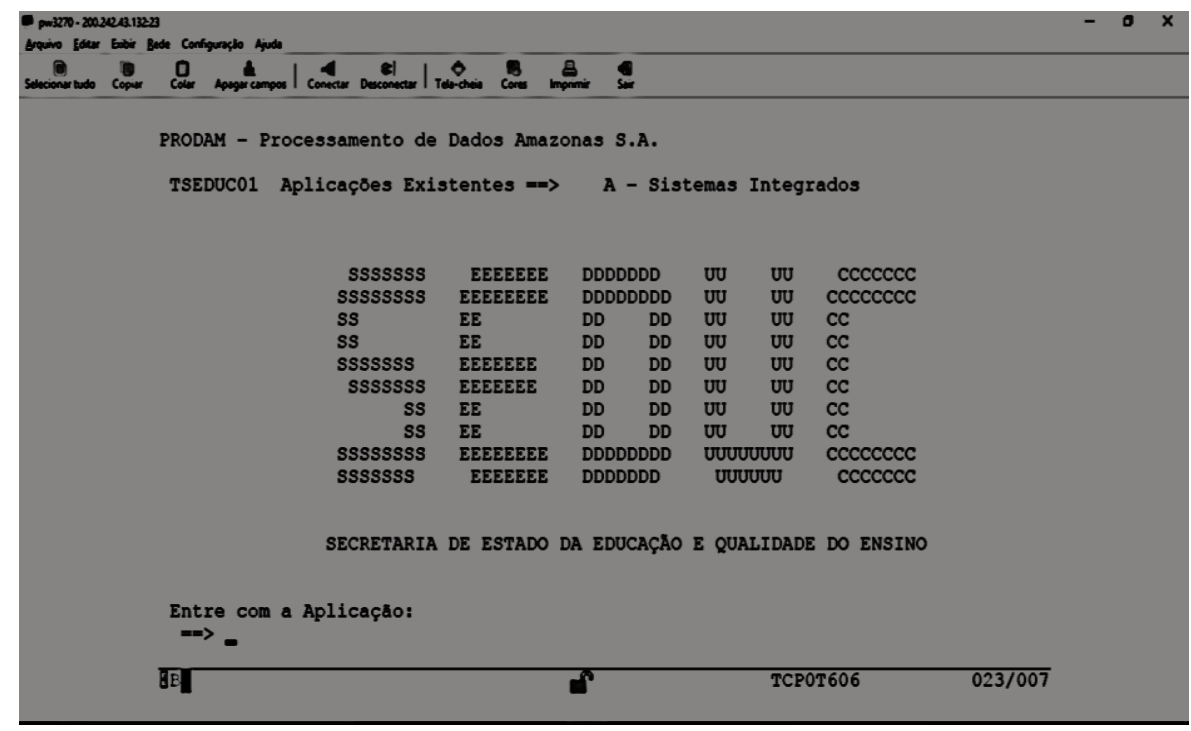

Fonte: Sigeam (2020)

Destaca-se que o sistema apresentou rejeição inicial, porém, o uso frequente, aliado ao conhecimento dos processos administrativos organizacionais da SEDUC/AM, acabou por minimizar os impactos da impossibilidade de inserção de recursos de usabilidade. Nos dias atuais, o sistema também funciona na internet, não sendo mais necessária a instalação de emulador, entretanto, continua com a mesma interface.

Quanto à parametrização do sistema, ela acontece, basicamente, na busca de 
reproduzir os processos físicos. Considera-se, portanto, as atividades realizadas na secretaria da escola, bem como as realizadas nos departamentos. Entretanto, levando em conta as necessidades particulares de cada setor, muitas vezes a coordenação do Sigeam demanda "possíveis" alterações (adequações e inovações de serviços) no sistema, sempre atenta à legislação vigente no que se refere aos processos existentes na administração e conforme necessidade de reprodução de processos, à empresa Processamento de Dados Amazonas S/A (PRODAM), e esta configura o sistema, a partir das definições advindas da SEDUC/AM.

O Sistema é integrado aos outros sistemas utilizados pela SEDUC/AM para a administração dos processos organizacionais, entre eles o Censo Educacional (Educacenso), o Sistema de Lotação de Servidores (SILS), o Sistema de Estruturas Curriculares (SEC), o Rendimento Web e o Portal Educacional, que permitem aos alunos e a seus pais ou responsáveisa visualização do boletim e do histórico escolar.

O Sigeam tem seu maior público de utilizadores nas escolas estaduais, entre secretários e gestores escolares, o que se deve, principalmente, ao seu caráter, fundamentalmente, de sistema acadêmico (SILVA, 2016). Além disso, devido à sua integração com o Educacenso, tornou-se indispensável para as atividades de rotina da secretaria da escola.

No que se refere à SEDUC/AM, o sistema é utilizado pelo Departamento de Gestão de Pessoas (DGP) para inserção, manutenção de informação de servidores, assim como alocação destes nas escolas e folha de pagamento. As gerências do Departamento de Políticas e Programas Educacionais (DEPPE) utilizam o sistema para consulta e impressão de relatórios no acompanhamento de programas e projetos educacionais desenvolvidos nas escolas. Além disso, a Gerência de Atendimento Específico Educacional à Diversidade (GAEED), que atende ao público do exame supletivo, inclui as informações do candidato e expede certificados pelo sistema que integra o Diário Digital, no qual são lançadas as notas, avaliações e todo o conjunto de ações congruentes a um diário de classe.

O Departamento de Gestão Escolar (DEGESC), por meio da Gerência de Monitoramento e Auditoria Escolar (GEMAE), faz a inclusão das estruturas curriculares e ensinos que são associados às escolas, o que confere ao sistema caráter documental, da mesma maneira que fornece um conjunto de estruturas e resoluções que regulamentam os ensinos no Amazonas. A Gerência de Programas, Projetos e Apoio ao Educando (GEPPAE) utiliza o sistema para obter dados cadastrais dos alunos e/ou professores. 
A Gerência de Acompanhamento aos Recursos Financeiros (GEARF), que é responsável pelo Programa Dinheiro Direto na Escola (PDDE), Associações de Pais, Mestres e Comunitários (APMC), os Programas Mais Educação e o Plano de Desenvolvimento da Escola (PDE), não utiliza o Sigeam, o que, em análise, poderia agilizar as atividades da gerência, visto que seria útil para o gerenciamento dos gastos das escolas, pois as informações contidas no sistema poderiam ser cruzadas para obter e mesmo entender as necessidades de cada escola.

O Departamento de Infraestrutura (DEINFRA) tem sob sua responsabilidade a coordenação, supervisão e acompanhamento da política de infraestrutura, gestão de obras e serviços de engenharia e de manutenção, gestão de patrimônio imóvel e de arquivos, administração do parque tecnológico, suporte técnico. Além disso, cabe também a ele assegurar a disponibilidade e o funcionamento dos sistemas de informação necessários à execução das atividades.

O referido departamento não utiliza o Sigeam e, em se tratando de acessibilidade arquitetônica, utiliza-se, poderia possibilitar maior assertividade no acompanhamento efetivo das escolas da rede. Visto que, segundo o Instituto Nacional de Estudos e Pesquisas Educacionais Anysio Teixeira (INEP), no Censo Escolar dos anos 2014 e 2015, - Amazonas possuía apenas 7\% de escolas com infraestrutura de acessibilidade, entre escolas estaduais, municipais e privadas, ocupando o último lugar entre escolas com acessibilidade no país. No todo, das escolas públicas do Amazonas, federais, estaduais e municipais, apenas 6\% possuem infraestrutura de acessibilidade como rampas, sinalização, corrimãos e 10\% contam com sanitários adaptados para deficientes.

Salienta-se, no entanto, que o Sigeam não oferece, até o momento, um serviço que sirva para o DEINFRA e para suas gerências acompanharem a chegada dos recursos do FNDE, para que possam, assim, preparar ou mesmo verificar os projetos previamente elaborados para as escolas no que se refere à estrutura de acessibilidade.

Sobre isso, Peinado (2016, p. 60) informa que, conforme pesquisa realizada com gestores, 114 (cento e catorze) gestores responderam que possuíam alguma infraestrutura acessível, notando-se certo desacordo com as informações pontuadas anteriormente.

das 238 escolas existentes em Manaus, 114 responderam ao questionário, ou seja, 49,9\%, e destas, 95\% responderam que possuem infraestrutura acessível, pelo menos rampa de acesso, tendo em vista que a questão ofereceu a possibilidade de escolher mais de uma opção. (PEINADO, 2016, p. 60) 
É importante ressaltar que a questão de infraestrutura é imprescindível para a inclusão. Nesse aspecto, os programas do governo federal "Escola Inclusiva" e "Escola Acessível" são programas que contemplam a acessibilidade arquitetônica e aportam recursos do Fundo Nacional de Desenvolvimento da Educação (FNDE), para as unidades escolares, por meio do Programa Dinheiro Direto na Escola (PDDE).

Em Manaus, segundo dados do Censo Escolar 2015, as escolas estaduais tinham 1.281 alunos incluídos e 1.686 alunos com necessidades especiais. Essa diferença se dá porque ainda existem escolas com atendimento específico exclusivo, como é o caso das Escolas Diofanto Monteiro e Augusto Carneiro que funcionam na cidade de Manaus.

Ainda, conforme relatório extraído do Sigeam, são 32 Salas de Recursos Multifuncionais (SRMF) - espaços que possuem mobiliário, materiais didáticos e pedagógicos, recursos de acessibilidade e equipamentos específicos para atendimento especializado educacional no contraturno - em 27 escolas, onde foram realizados, até 27 de maio de 2016, 96 atendimentos (Sigeam, 2019).

No Amazonas, são 660 escolas estaduais, por força da legislação vigente, devem fazer atendimento inclusivo, ou seja, garantir acesso e permanência a todos os alunos com necessidades especiais que, porventura, as procurarem. Nesse total, estão inseridas as escolas da capital e do interior, entretanto, nem todas possuem alunos com necessidades especiais.

O Departamento de Gestão Financeira (DPGF) colabora no aprimoramento do sistema por meio da Gerência de Estudos e Pesquisas Educacionais (GEPES), que busca a cada melhoria, adequar o sistema para uma migração eficiente dos dados para o sistema Educacenso, o setor também é responsável pela coordenação de matrícula. Finalmente, o Departamento de Logística (DELOG) também utiliza o sistema para verificar demanda por merenda, kits escolares, fardamento etc.

Quanto à elaboração do Sigeam, a princípio, a ideia era que o sistema oferecesse módulos de serviços direcionados às atividades que acontecem na administração da escola, bem como na esfera departamental da SEDUC/AM. No entanto, atualmente, observa-se que o sistema oferece alguns serviços que não são utilizados e, por outro lado, não oferecem serviços que poderiam melhorar a gestão tanto nas escolas quanto nos departamentos, como é o caso do DEINFRA, anteriormente mencionado. Com o objetivo de aprofundar-se na utilização do sistema, o próximo tópico versará sobre os usos do módulo Especial. 


\subsection{Usos do módulo Especial}

O Especial é um módulo do Sigeam desenvolvido, inicialmente, com o objetivo de produzir relatórios para serem utilizados pela GAEE e pelas escolas. Os relatórios disponibilizam informações para o acompanhamento situacional (matrícula, atendimento, tipos de especificidades, local de atendimento, informações cadastrais do aluno, avaliação multiprofissional, sala de recurso etc.) dos alunos da rede estadual com necessidades especiais, com potencial de permitir ações corretivas e pontuais pela GAEE.

Apesar de o sistema ter sido desenvolvido para atendimento deste público, a gerência não se apropriou das funcionalidades, encaminhando suas demandas por relatórios, para a Coordenação do Sigeam, que os expedia, permitindo aos supervisores que mantinham contato com as escolas, interagindo e apoiando os gestores e os secretários escolares, um amplo conhecimento do módulo Especial e de suas possibilidades.

Quanto às suas especificidades, o módulo tem inserido em suas funcionalidades, serviços de acompanhamento (Relatórios) das atividades para a gestão deste público, conforme pode ser observado no quadro 1:

\section{Quadro 1 - GERESPEC - Relatórios disponíveis no módulo Especial}

\begin{tabular}{|l|l|l|}
\hline № & Mnemônico & Relatórios/Resumo \\
\hline 1 & RELINCLU & Relação de Alunos Incluídos \\
\hline 2 & RELRECUR & Relação de Salas de Recurso \\
\hline 3 & RELTUINC & Relação de Turmas Inclusivas \\
\hline 4 & RELNECES & $\begin{array}{l}\text { Resumo Alunos Matriculados com Necessidades } \\
\text { Especiais }\end{array}$ \\
\hline 5 & RELNECGE & $\begin{array}{l}\text { Resumo Alunos Matriculados com Necessidades } \\
\text { por Gênero }\end{array}$ \\
\hline 6 & RELALKIT & Resumo de Alunos que receberam Kit Especial \\
\hline 7 & RELESCIN & $\begin{array}{l}\text { Resumo Necessidades Especiais por Escola } \\
\text { Inclusiva }\end{array}$ \\
\hline
\end{tabular}

Fonte: Elaborado pela autora.

O módulo Especial fornece informações importantes para o gerenciamento da educação especial, tanto em nível da gestão escolar quanto em nível macro da SEDUC/AM, como localização dos alunos com necessidades especiais, informações de turno, turma e professor. Além disso, o sistema, se alimentado corretamente, oferece, ao gestor escolar, informações sobre os medicamentos utilizados pelo aluno com necessidade especial.

$\mathrm{Na}$ garantia das políticas públicas, é indispensável que o gestor conheça a Revista Amazônida, Manaus, AM, vol. 6, n 1. p. 01 - 21, 2021 
realidade da escola e, é nessa perspectiva que o sistema pode colaborar com a administração, fornecendo dados acerca das dimensões em que a escola se encontra com relação à educação especial. Para Lück:

[...] o conceito de gestão está associado ao fortalecimento da democratização do processo pedagógico, à participação responsável de todos nas decisões necessárias e na sua efetivação mediante um compromisso coletivo com resultados educacionais cada vez mais efetivos e significativos. (LÜCK, 1997, p. 3)

Todavia, apenas relatórios são insuficientes, é preciso que o sistema se adeque às legislações também em outros contextos, como é o caso da matrícula. No que concerne a isso, a Resolução no 138/2012 - CEE/AM, ao regulamentar a educação inclusiva para as escolas estaduais do Amazonas, com o objetivo de normatizar e garantir educação equitativa aos educandos com deficiências, transtornos globais e Altas Habilidades/Superdotação, delimita muito bem as questões relativas a essa temática.

Quanto ao sistema, o Especial é um módulo voltado para o registro das necessidades especiais dos alunos. Os registros dessas informações fornecem ao gestor um maior conhecimento sobre as especificidades dessa clientela, ampliando as possibilidades para uma gestão estratégica mais eficiente dos alunos da educação especial.

Ademais, as informações disponíveis no sistema permitem que a SEDUC/AM possa fazer articulações a fim de atender com a qualidade este público. Como se pode perceber no quadro 2.

Quadro 2 - Representativo do módulo Especial

\begin{tabular}{|l|l|l|}
\hline No & Mnemônico & Serviço \\
\hline $\mathbf{1}$ & MALAVISU & Manutenção Laudo Visão Aluno \\
\hline $\mathbf{2}$ & COLAVISU & Consulta Laudo Visão Aluno \\
\hline $\mathbf{3}$ & MAVAFUN & Manutenção Avaliação Funcional Aluno \\
\hline $\mathbf{4}$ & CAVALFUN & Consulta Avaliação Funcional Aluno \\
\hline $\mathbf{5}$ & MATENALU & $\begin{array}{l}\text { Manutenção de Turma/Aluno Atendimento } \\
\text { Especializado }\end{array}$ \\
\hline $\mathbf{6}$ & CATENALU & Consulta Atendimento Especializado Aluno \\
\hline $\mathbf{7}$ & REMUPROF & Registro Avaliação Multiprofissional Aluno \\
\hline $\mathbf{8}$ & COMUPROF & Consulta Avaliação Multiprofissional Aluno \\
\hline $\mathbf{9}$ & CONATEPE & Consulta Atendimentos por Período \\
\hline $\mathbf{1 0}$ & GERESPEC & Relatórios Gerenciais \\
\hline
\end{tabular}

Fonte: Elaborado pela autora.

O sistema é alimentado pelo setor administrativo da escola, a secretaria, sendo assim, o gestor não é quem realiza a matrícula do aluno na escola, mas na maioria das escolas do Amazonas é quem responde, inclusive pelo setor pedagógico, ou seja, precisa 
ter domínio dessas informações. Sendo assim, pode ter acesso às informações por meio de consultas e pelos relatórios disponibilizados pelo sistema.

No concernente às legislações, a educação especial e inclusiva, na Lei Federal № 13.146, de 6 de julho de 2015, assegura o atendimento inclusivo nos sistemas de ensino, em todos os níveis e modalidades, e estabelece a utilização de Projeto Político Pedagógico e a institucionalização do atendimento especializado, com introdução de profissionais de apoio (BRASIL, 2015). Por isso, percebe-se que mecanismos de gerenciamento da inclusão são ferramentas indispensáveis.

Da mesma forma, verifica-se que as redes públicas, estadual e municipal de Manaus, de ensino, utilizadoras do Sigeam, ainda não utilizam o sistema devidamente, melhor dizendo, não tem o sistema parametrizado em conformidade com o que prediz a legislação.

Nesse sentido, quando o assunto é educação especial, a Resolução nํ 138/2012 é utilizada na parametrização do sistema; entretanto, em se tratando de matrícula dos alunos com necessidades especiais, percebe-se essa situação quando se observa a matrícula do aluno com necessidade especial. Caso o sistema fosse parametrizado conforme determina a Resolução, o impacto da matrícula dos alunos com necessidades especiais mostrar-se-ia particularmente vigoroso, pois a referida Resolução estabelece que quando as turmas receberem estes alunos, outros tantos deverão ser subtraídos. Conforme o Artigo $\mathrm{n}^{0}$ 12, Inciso II, as classes comuns com inclusão de alunos com necessidades especiais deverão ter a capacidade pedagógica conforme o quantitativo definido no quadro 3.

Quadro 3 - Número de alunos por fase/turma

\begin{tabular}{|c|c|}
\hline Fases/séries & Alunos \\
\hline $1^{\circ}$ ano & 20 alunos por sala \\
\hline $2^{\circ}$ ao $3^{\circ}$ ano & 25 alunos por sala \\
\hline $4^{\circ}$ e $5^{\circ}$ anos & 16 alunos por sala \\
\hline $6^{\circ}$ ao 9 ano & 35 alunos por sala \\
\hline Ensino médio & 35 alunos \\
\hline
\end{tabular}

Fonte: Elaborado pela autora, a partir da Resolução 138/2012 CEE/AM (2016).

Atualmente, quando um aluno com necessidade especial é matriculado, o sistema reduz 02 vagas, sem consistir ensino ou fase da matrícula, ou seja, o que ocorre na prática é que mesmo com a matrícula de um aluno com necessidade especial, a sala 
ainda é ocupada considerando apenas o critério "espaço". Dessa forma, o que se nota, é que se a sala possui 40 metros quadrados, terá sua capacidade máxima ocupada, incluindo alunos com necessidades especiais. Entretanto, a Resolução nำ 138/2012 do CEE/AM estabelece que o sistema deveria reduzir a quantidade de alunos na turma proporcionalmente à matrícula de alunos com necessidades especiais, considerando ensino e fase.

Por causa dessa situação, ao professor resta uma sala superlotada de alunos somados àqueles que necessitam de acompanhamento especial. Algumas vezes, é possível contar com o apoio de outro profissional, o auxiliar da vida escolar, que sobrevém em cumprimento às determinações legais. No entanto, graças à lentidão dos processos e ao desconhecimento das necessidades das escolas pelo pessoal do DGP, que poderia ter acesso às informações por meio de relatórios gerados pelo sistema, a partir do registro de informações preenchidas no ato da matrícula, o profissional não é encaminhado em tempo hábil para a escola. Sendo assim, como agir considerando que o sistema não reduz as vagas conforme o que estabelece a Resolução no 138/2012?

Deste modo, nota-se que não é apenas questão de ter um sistema informatizado ou legislações, mas também que o sistema esteja disponível e seus serviços sejam acessíveis a todos da administração e que as legislações sejam respeitadas. Nesse sentido, é necessário reconhecer que o acesso à informação possibilita ao gestor uma administração mais efetiva e democrática, pois além de proporcionar mais transparência e celeridade aos processos ocorridos na escola, o que viabiliza aprimoramento das atividades singulares à gestão, também o professor, em decorrência disso, tem suas necessidades profissionais melhor acompanhadas e na ponta, o aluno com necessidades especiais pode receber uma educação de melhor qualidade.

Na sequência, será abordado o uso das NTICs na SEDUC/AM, com foco na educação especial. Além do Sigeam, apresentam-se os sistemas a ele integrados para explicitar como se dá a utilização desses recursos tecnológicos.

\subsection{As NTDICs na SEDUC/AM}

Ao longo da última década, a educação especial passou a ocupar um significativo espaço nas políticas e ações da SEDUC/AM decorrente, fundamentalmente, das exigências demandadas da sociedade, sustentadas na concepção da inclusão de alunos com necessidades especiais no sistema de ensino da secretaria.

$\mathrm{Na}$ implementação de ações, com o uso das NTDICs, a SEDUC/AM criou e Revista Amazônida, Manaus, AM, vol. 6, n 1. p.01 - 21, 2021 
institucionalizou o Sigeam que, com a inserção do módulo Especial, poderia possibilitar e institucionalizar a matrícula e a visualização concreta das demandas de alunos com necessidades especiais, como também poderia aperfeiçoar seu atendimento pedagógico por meio de ferramentas administrativas disponibilizadas para a utilização dos gestores escolares. O que se nota, nesse sentido, é que se por um lado o Sigeam, com o módulo Especial, ampliaria as possibilidades de inclusão e o atendimento dos alunos com necessidades especiais, por outro, poderia apontar os desafios a serem enfretados no que se refere à apropriação e ao uso de suas ferramentas para a SEDUC/AM, professores, pedagogos e gestores.

Observa-se então que as NTDICs poderiam fornecer suporte tecnológico para a administração escolar, em nível de gestão. Nesse contexto, a SEDUC/AM também estabeleceu o Diário Digital (DD), o qual é utilizado pelo professor, podendo ser acompanhado pelo pedagogo da escola, pelo gestor e pela coordenadoria distrital (setor departamental, responsável pelas escolas, divididas por zona). Além do DD, a escola conta com acesso ao Rendimento Web, que é um site que possibilita dados e gráficos das escolas quanto ao rendimento dos alunos e que como o DD está integrado ao Sigeam.

O site de matrículas é outra ferramenta que está integrada ao Sigeam e é disponibilizada na web, também por meio de aplicativos para dispositivos móveis. Nele, os alunos podem realizar seu cadastro e matrícula para qualquer escola da rede estadual do Amazonas e municipais de Manaus, de qualquer lugar do país ou do mundo, estando condicionada sua confirmação de matrícula à entrega de documentos na escola pretendida nas datas definidas em calendário de matrícula.

Também, no site de matrículas, o aluno com necessidade especial indica ter a necessidade, e o sistema guarda automaticamente a informação no Sigeam. Para Vieira:

Saber a origem dos alunos, seus conhecimentos prévios sobre o assunto a ser estudado, seus interesses, suas dificuldades, o grau de envolvimento dos pais na educação/formação do aluno, a cultura e os valores da família, o portfólio de trabalhos realizados, as notas e as ocorrências anteriores em sua vida escolar, dentre outras informações são cada vez mais relevantes se queremos ajustar melhor nossa proposta para um grupo específico de aprendizes.

Nesse ambiente organizacional, os principais recursos para a obtenção de bons resultados e o cumprimento dos objetivos pretendidos são o acesso à informação e a capacidade de sua manipulação e análise, não somente pela direção e coordenação, mas por todos os elementos envolvidos na formação dos alunos. (VIEIRA, 2003, p. 132)

Nessa perspectiva, a SEDUC/AM produziu novos serviços nas plataformas 
tecnológicas existentes, para o auxílio de gestores, possibilitando acesso à informação e o transformar da realidade de sua escola. Sobre isso, Almeida (2003, p. 38) diz que a utilização das NTICs se deu na educação com o objetivo de possibilitar controle e gestão técnica, mas que se percebeu no decorrer de sua utilização que a articulação da escola com outros espaços produtores de conhecimento poderia resultar em transformações relevantes, convertendo a escola em um espaço aberto e flexível, possibilitando uma gestão participativa.

Almeida (2003, p. 44-51) também reflete sobre a necessidade de gestão das tecnologias na instituição escolar. Para ele deve envolver a gestão pedagógica e administrativa, na qual o gestor tem papel indispensável em seu estabelecimento e manutenção.

As NTDICs permeiam não apenas a administração escolar, no âmbito pedagógico ou administrativo, como também demonstram ser ferramentas facilitadoras às especificidades dos alunos deficientes e/ou com necessidades especiais. Contudo, o foco deste artigo é o Sigeam, as possibilidades e os desafios que envolvem sua utilização pelos gestores escolares e percebe-se as NTIDCs como primordiais para 0 estabelecimento de uma gestão célere e transparente, pois, apesar dos avanços tecnológicos, ainda se percebe que as escolas não se apropriaram devidamente de seu uso. Sobre isso, Moran diz:

As mudanças na educação dependem também de administradores, diretores e coordenadores mais abertos, que entendam todas as dimensões do processo pedagógico [..] que apoiem os professores inovadores; que equilibrem o gerenciamento empresarial, tecnológico e humano, contribuindo para que haja um ambiente de maior inovação, intercâmbio e comunicação. (MORAN, 2012, p. 29)

À vista disso, de volta à conjuntura de uma ferramenta integradora, percebe-se que um sistema informatizado, acessível, que forneça informações e demonstre a situação do público com necessidades especiais nas escolas, contribuiria sobremaneira para que a escola compreendesse o alcance das políticas públicas, assim como permitiria também mensurar de forma mais aproximada o cumprimento das legislações, municiando os gestores de fundamentação para reivindicar direitos, além de possibilitar a definição de estratégias para a recepção desse público.

No percurso deste artigo, apresentou-se, primeiramente, o cenário da educação especial, em seguida, discorreu-se acerca da Resolução ํo 138/2012, posteriormente, explanou-se sobre o Sigeam e os usos do módulo Especial e, finalmente, sobre as NTDICs na SEDUC/AM. 


\section{CONSIDERAÇÕES FINAIS}

Este artigo teve por objetivo apresentar o módulo Especial do Sigeam enquanto ferramenta tecnológica para a gestão administrativa e pedagógica dos processos de inclusão da pessoa com necessidades especiais nas escolas públicas do estado do Amazonas.

No percurso de organização da presente pesquisa, foi possível perceber que a educação especial precisa de maior atenção por parte dos tomadores de decisão, não apenas por envolver estudantes com deficiências, mas também aqueles com necessidades especiais e uma centena de outras dificuldades que requerem atenção especial do professor e da gestão (COSTA, 2012).

Além da educação especial, esta pesquisa também abordou o uso do módulo Especial do Sigeam, que é um sistema valioso e que tem sido utilizado pela SEDUC/AM para facilitar a gestão escolar, mas que precisa ser olhado sob uma perspectiva mais pedagógica, pois pode fornecer mais subsídios aos gestores e pedagogos para que possam realizar seu trabalho de forma célere, transparente e propiciar melhor aproveitamento do tempo.

Para uma visão mais aproximada, foi necessário revisitar o Sigeam, como sistema e coordenação. Nesse sentido, foram percebidas grandes diferenças quanto à dinâmica do atendimento recebido pelas escolas. Além disso, foi possível perceber que muitas das certezas desta pesquisadora foram confirmadas e outras refutadas, o que contribuiu para o crescimento profissional e a ampliação do cabedal de conhecimento sobre esta temática.

Além disso, pondera-se que o sistema poderia ser utilizado por pedagogos e professores, com a SEDUC/AM possibilitando não apenas treinamento para utilização do sistema, como também apresentando as possibilidades quanto ao uso dos dados resultantes disso. Ademais, no que concerne ao aprimoramento do próprio sistema, acredita-se que a coordenação do sistema poderia, a partir dos gabinetes de gestão e pedagógico, "conversar" com os departamentos, gerências e coordenações, com intuito de propiciar maior integração no sistema, atendendo às necessidades de cada setor, o que possibilitaria não apenas a integração, como também transparência de ações da SEDUC/AM como um todo.

Do mesmo modo, acredita-se que esta pesquisa possa servir para mostrar o cenário em que se encontra o uso das NTDICs nas escolas do Amazonas, bem como 
para demonstrar que a tecnologia pode auxiliar sobremaneira a gestão escolar. Igualmente, considera-se que a utilização de um sistema desenvolvido especificamente para o atendimento de um público tão seleto, possa propiciar uma gestão mais eficiente e integrada.

Desta maneira, também se espera que esta pesquisa possa subsidiar tomadas de decisão dos gestores da SEDUC/AM, enquanto macrossistema e dos gestores escolares enquanto microssistema.

Finalmente, quanto ao módulo Especial, constatou-se que, embora se trate apenas de um menu de serviços voltados para a gestão do aluno com necessidade especial, nota-se que sua utilização pode alavancar o fortalecimento da educação especial e promover um melhor atendimento para este público. É importante destacar que não só se acredita no Sigeam como ferramenta de integração, mas também por ter, entre seus serviços, o respectivo módulo, espera-se que ele possa ser utilizado devidamente, fornecendo informações em tempo e, o mais importante, possibilitando a utilização desses dados para uma educação mais eficiente.

\section{REFERÊNCIAS}

ALMEIDA, Maria Elizabeth Bianconcini de. Tecnologias e Gestão do Conhecimento na Escola. In: Gestão educacional e tecnologia. Organizadores: Alexandre Thomaz Vieira, Maria Elizabeth Bianconcini de ALMEIDA, Myrtes Alonso. São Paulo: Avercamp, 2003.

AMAZONAS. Conselho Estadual de Educação do Amazonas - CEE/AM. RESOLUÇÃo №138/2012. $<$ http://cee.am.gov.br/?option=com_phocadownload\&view=category\&id=23:2012\&ltemid= 194> . Acesso em: 27jul. 2020.

AMAZONAS. Plano Estadual de Educação. Meta 4. Disponível em:<http://portal.mec.gov.br/seb/arquivos/pdf/pee_am.pdf> . Acesso em: 27jul. 2020.

AMAZONAS. Sistema Integrado de Gestão Educacional - SIGEAM. Acesso em: 03 nov. 2020.

BRASIL. Decreto no. 3.298 de 20 de dezembro de 1999. Regulamenta a Lei no 7.853, de 24 de outubro de 1989 . Disponível em:<https://www.planalto.gov.br/ccivil_03/decreto/D3298.htm> . Acesso em: 27jul. 2020.

BRASIL. Escola Acessível e Escola inclusiva. Disponível em: $<$ http://portal.mec.gov.br/index.php?option=com_docman\&view=download\&alias=13290doc-orient2013\&category_slug=junho-2013-pdf\&ltemid=30192> . Acesso em: 27jul. 2020.

BRASIL. Estatuto da pessoa com deficiência. Lei 13.146, de 6 de julho de 2015. Disponível em: <http://www.planalto.gov.br/CCIVIL_03/_Ato2015- 
2018/2015/Lei/L13146.htm>. Acesso em: 20 mai. 2020.

BRASIL. Fundo das Nações Unidas para a Infância. Portal da UNICEF. Declaração Mundial sobre Educação para Todos: Satisfação das Necessidades Básicas de Aprendizagem. Disponível em:<https://www.unicef.org/brazil/declaracao-mundial-sobreeducacao-para-todos-conferencia-de-jomtien-1990> . Acesso em: 27jul. 2020.

BRASIL. Lei de Diretrizes e Bases da Educação Nacional. Lei o 9.394/96, de 20 de dezembro de 1996. Estabelece a Lei de diretrizes bases da educação. Disponível em: $<$ https://www2.senado.leg.br/bdsf/bitstream/handle/id/70320/65.pdf>. Acesso em: 20 mai. 2020.

BRASIL. Lei no. 7.853, de 24 de outubro de 1989. DF. Brasília. Disponível em: <https://www.planalto.gov.br/ccivil_03/Leis/L7853.htm> . Acesso em: 20 mai. 2020.

BRASIL. Plano Nacional de Educação. Plano Nacional de Educação 2014-2024 [recurso eletrônico]: Lei no 13.005, de 25 de junho de 2014. Disponível em: < http://www.planalto.gov.br/ccivil_03/_Ato2011-2014/2014/Lei/L13005.htm>. Acesso em: 20 jul. 2020.

BRASIL. Plano Nacional de Educação. Meta 4. Disponível em: <https://www.observatoriodopne.org.br/indicadores/metas/4-educacao-especialinclusiva/indicadores>. Acesso em: 27 JUL 2020.

BRASIL. Portal do MEC. Liberados recursos para adequar as escolas a alunos com deficiência. 2011. Disponível em: <https://www.fnde.gov.br/index.php/acesso-ainformacao/institucional/area-de-imprensa/noticias/item/2391-liberados-recursos-paraadequar-as-escolas-a-alunos-com-defici\%C3\%AAncia . Acesso em: 27jul. 2020.

BRASIL. Resolução CNE/CEB n. 2, de 11 de setembro de 2001. Conselho Nacional de Educação. Câmara de Educação Básica. Brasília: CNE/CEB, 2001c. Disponível em:< http://portal.mec.gov.br/cne/arquivos/pdf/CEB0201.pdf> . Acesso em: 23 jul. 2020.

COSTA, N. F. Dificuldades de Aprendizagem: UM ESTUDO DOCUMENTAL. 77fls. Trabalho de Conclusão de Curso (Graduação em Pedagogia) - Universidade Estadual de Maringá, Maringá, 2012. Disponível em: <http://old.dfe.uem.br/TCC/Trabalhos_2012/NAYARA_FERREIRA_DA_COSTA.PDF>. Acesso em: 20 ago. 2020.

DUTRA, Cláudia. P.; GRIBOSKI, Cláudia M. Gestão para Inclusão. Revista de Educação especial, Santa Maria, n. 26, p. 9-17, 2005. Disponível em:<https://periodicos.ufsm.br/educacaoespecial/article/view/4372> . Acesso em: 02 jun. 2017

ESTEVÃO, Carlos. Gestão Estratégica nas escolas. Coleção: Cadernos de Organização e Gestão Curricular. 2000. Disponível em: < http://www.crmariocovas.sp.gov.br/pdf/pol/gestao_estrategica.pdf>. Acesso em: 26 mai. 2017.

GOERGEN, Pedro. In JANNUZZI, Gilberta S. de M. A educação do deficiente no Brasil: dos primórdios ao início do século XXI. 3 ed. Campinas: Editora Autores associados 
LTDA, 2012.

INEP. CENSO ESCOLAR 2014. Disponível em: <http://download.inep.gov.br/educacao_basica/censo_escolar/notas_estatisticas/2017/not as_estatisticas_do_censo_escolar_2014\%20final.pdf >. Acesso em: 11 ago. 2020.

INEP. CENSO ESCOLAR 2015.2 Disponível em: <http://download.inep.gov.br/educacao_basica/censo_escolar/notas_estatisticas/2017/not as_estatisticas_do_censo_escolar_2015_matriculas.p̄pdf >. Acesso em 11 ago. 2020.

LÜCK, Heloisa. A evolução da gestão educacional, a partir de mudança paradigmática. Revista Gestão em Rede, n. 03, p. 13-18, nov. 1997. Disponível em: < http://docplayer.com.br/21263478-A-evolucao-da-gestao-educacional-a-partir-demudanca-paradigmatica.html>. Acesso em: 20 jul. 2020.

MINAYO, Maria Cecília de Souza (org.). Pesquisa Social. Teoria, método e criatividade. 18 ed. Petrópolis: Vozes, 2001.

MORAN, José Manuel. A educação que desejamos: novos desafios e como chegar lá. 5 ed. Campinas: Editora Papirus, 2012.

PEINADO. Ana Patricia e Silva. Sistema integrado de gestão educacional do amazonas: desafios e possibilidades na utilização do módulo especial. Dissertação (mestrado profissional) - Universidade Federal de Juiz de Fora, Faculdade de Educação/CAEd. Programa de Pós-graduação em Gestão e Avaliação da Educação Pública. p. 107. 2017.

SILVA, Tiago Lima e. Possibilidades de uso do sistema integrado de gestão educacional do Amazonas na gestão das escolas. Dissertação (mestrado profissional) - Universidade Federal de Juiz de Fora, Faculdade de Educação/CAEd. Programa de Pós-graduação em Gestão e Avaliação da Educação Pública. p. 137. 2016.

UNESCO. Declaração de Salamanca. Dispõe sobre princípios, políticas e práticas na área das necessidades educativas especiais. Salamanca-Espanha, 1994. Disponível em: <http://portal.mec.gov.br/seesp/arquivos/pdf/salamanca.pdf>. Acesso em: 26 mai. 2020.

UNESCO. Declaração mundial sobre educação para todos e plano de ação para satisfazer as necessidades básicas de aprendizagem. Jomtien/Tailândia, 1990. Disponível em: <http://unesdoc.unesco.org/images/0008/000862/086291por.pdf>. Acesso em: 26 mai. 2020.

VIEIRA, Alexandre Thomas. Construindo uma nova escola. In: VIEIRA et al. Formação de gestores escolares para a utilização de tecnologias de informação e comunicação. São Paulo, SP: Takano Editora e Gráfica, 2002.

Artigo recebido em: 17 de JANEIRO de 2021.

Aceito para publicação em: 20 de JUNHO de 2021. 
Manuscript received on: JANUARY 17, 2021

Accepted for publication on: JUNE 20, 2021

Endereço para contato: Universidade Federal do Amazonas, Faculdade de Educação/FACED, Programa de PósGraduação em Educação, Campus Universitário, Manaus, CEP: 69067-005, Manaus/AM, Brasil 